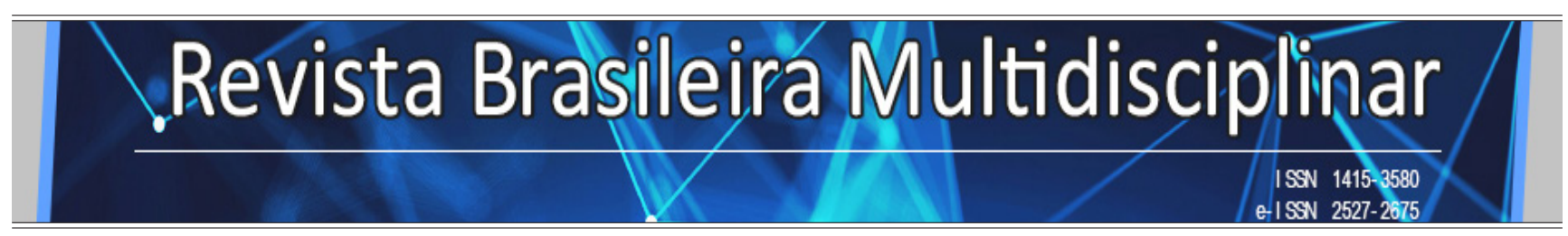

http://revistarebram.com/index.php/revistauniara

\title{
ENTRE CANTEIROS E ERVAS: UM ESTUdO DA PRODUÇÃo DE ERVAS MEDICINAIS A PARTIR DE INDICAÇÃo DO INTERESSE do SUS- SiSTEMa ÚNICO DE SAÚdE
}

Thauana Paiva de Souza Gomes*; Dulce Consuelo Andretta Whitaker; Vera Lúcia Silveira Botta Ferrante

${ }^{*}$ Cientista Social, Pedagoga, Mestre e Doutora em Educação Escolar, Pesquisadora NUPEDOR e Docente Estácio.

** Docente do programa da Pós-graduação de Desenvolvimento Territorial e Meio Ambiente.

*** Docente e Coordenadorra do programa da Pós-graduação de Desenvolvimento Territorial e Meio Ambiente.

*Autor para correspondência e-mail: thauanap@gmail.com

\section{Palavras-chave}

\section{Mulheres}

Assentamento

Saberes

Ervas medicinais

\section{KEYWORDS}

Women

Settlement

Knowledge

Medicinal herbs

\section{RESUMO}

O presente trabalho é parte de estudos do doutorado que transformou a pesquisa em um produto material de ação social. O trabalho buscou o aprofundamento dos saberes, práticas de usos de ervas medicinais utilizados por mulheres assentadas do Monte Alegre comparada aos usos e indicações orientadas pelo SUS- Sistema Único de Saúde. Através de entrevistas e depoimentos com mulheres, bem como visita aos lotes, levantou-se um inventário da produção, formas de consumo, utilizações e os tipos de ervas produzidos por estas mulheres. No que se refere propriamente à fundamentação teórica buscou-se discutir questões relativas às orientações legais dos usos destas ervas no SUS em relação à prática das assentadas. Embora os usos ligados às ervas pelas mulheres estejam ligados aos hábitos tradicionais, é possível perceber, nas orientações legais, uma articulação entre o uso tradicional e o racional da área médica. Por fim, o trabalho buscou mostrar a relação entre saberes tradicionais e as orientações legais, evidenciando o importante papel da tradição para novas estudos e validação científica/ médica.

\section{Abstract}

BETWEEN FLOWERBEDS AND HERBS: A STUDY OF THE PRODUCTION OF MEDICINAL HERBS BASED ON AN INDICATION OF THE INTEREST OF SUS - SisTEMa ÚNiCO DE SAÚdE

The present work is part of studies of the doctorate that transformed research into a material product of social action. The basically qualitative work sought to deepen the knowledge, practices of uses of medicinal herbs used by settled women of Monte Alegre compared to the uses and indications guided by SUS. Through interviews and testimonies with women, as well as visits to the lots, an inventory of the production, forms of consumption, uses and the types of herbs produced by these women were collected. As far as the theoretical basis is concerned, we sought to discuss issues related to the legal guidelines of the uses of these herbs in the SUS in relation to the practice of the settlers. Although the herbal uses of women are linked to traditional habits, it is possible to perceive, in legal guidelines, an articulation between the traditional and rational use of the medical area. Finally, the work sought to show the relationship between traditional knowledge and legal guidelines, highlighting the important role of tradition for new studies and scientific / medical validation. 


\section{INTRODUÇÃo}

O presente trabalho é parte do doutorado desenvolvido em comunidades rurais do assentamento de Monte Alegre da região de Araraquara, em particular com mulheres assentadas produtoras que produzem ou utilizam ervas medicinais. O presente recorte destaca uma revisão da arte de trabalhos produzidos ligados a mulheres assentadas, ervas medicinais, comparadas a um inventário realizado aos usos e indicações orientadas pelo SUS- Sistema Único de Saúde.

Ao verificar o papel das mulheres nos assentamentos com relação ao meio ambiente destaca-se a importante relação das mesmas no processo de conservação ambiental, permanência e transferência de saberes agroecológicos.

A força com que os processos de utilização dos agroquímicos chegam aos assentamentos, promovendo constrangimentos às formas tradicionais de usos da terra, leva os assentados e assentadas a esquecerem da relação anterior e quase simbiótica com o meio ambiente (GOMES, 2015), posto que a maneira "eficiente" de como o pacote tecno-agroquímico, composto por sementes melhoradas, mecanização, insumos químicos e biológicos, viabilizando a modernização agropecuária, aumentando a produção por meio da padronização em bases industriais, com discurso da produtividade e lucratividade ${ }^{1}$, faz os pequenos produtores buscarem tal eficiência produtiva, embora percebam o ônus que acarretará à vida (GOMES, 2015).

A partir desta orientação, os saberes tradicionais e os conhecimentos adquiridos de forma geracional através do vivenciamento com a natureza, predominante nas atividades femininas, são substituídos por práticas artificializadas e sintéticas. Vale ponderar que parte destes pequenos produtores não percebe os impactos e males dos usos destas práticas, ou mesmo os desconhece, por falta de informação, mas uma outra parcela, consciente de todos os problemas trazidos pelo uso de pesticidas e inseticidas, continua a executar tais práticas, iludidos pelas promessas de produtividade.

Neste aspecto, o papel feminino no processo histórico é duplamente importante: primeiro, por ser, em grande medida, responsável pela permanência da resistência de práticas alternativas frente ao sistema da agricultura convencional, e segundo, pelo fato de as mulheres manterem vivo e repassarem um conhecimento sobre saúde, criação e meio ambiente mais sustentável às novas gerações.

Muitas das práticas naturais que a ciência tem chamado de Agroecologia têm se conservado e sido praticadas em quintais, áreas da agrovila, pomares, sítios, hortinhas, lugares nos quais a figura feminina prevalece como ponto central na organização e cuidado, no sentido mais afetivo desta palavra (GOMES, 2015).

Neste trabalho buscamos apresentar a revisão da arte e um inventário de ervas identificadas nas práticas variadas de utilização e cuidados com a saúde animal e humana, através das ervas plantadas nos quintais pelas mulheres dos assentamentos Bela Vista.

\section{Metodologia}

Para desenvolvimento da presente pesquisa, foram realizados dois caminhos para revisão bibliográfica, os quais nos presentearam com resultados incrivelmente interessantes e importantes com relação às pesquisas destinadas às mulheres em assentamentos de reforma agrária. Bem como, inventário produtivo de lotes de mulheres do assentamento Monte Alegre de Araraquara São Paulo.

Sendo assim, a primeira etapa realizada foi a busca do que se encontra disponível na plataforma da CAPES- Coordenação de Aperfeiçoamento de Pessoal de Nível Superior de teses e dissertações, na qual se trabalhou com o intervalo de análise de 2011 a 2016. O segundo caminho desenvolvido foi a análise do "Levantamento Bibliográfico Gênero no meio rural" realizado pelo IPEA- Instituto de Pesquisa Econômica Aplicada sobre a literatura disponível quanto às questões de gênero no meio rural até o ano de 2009.

${ }^{1}$ Não nos cabe julgar aqueles que, pressionados pelo sistema, aderem aos processos destrutivos do Capital. Nosso objetivo é estudar as resistências ao processo. 
É preciso salientar que, ao analisar as produções que têm como marco o ano de 1979 (com o primeiro registro de dissertação disponível encontrado) até o ano de 2016, as produções relacionadas às questões de gênero em assentamentos e relacionados às ervas medicinais foram crescentes. Com relativo salto nos governos progressistas (a partir de 2003 a 2015), fato a exigir uma análise bastante precisa do cenário político, das políticas públicas, dos avanços sociais do período e, em especial, do aumento de destinação de recursos para agências de fomento de pesquisa e ampliação de investimentos em educação para o segmento do campo.

A segunda etapa foi um inventário de 22 lotes de mulheres do assentamento Monte Alegre de Araraquara, no qual se buscou avaliar as formas de usos e plantios das ervas medicinais, bem como levantamento das ervas descritas e regulamentadas pela ANVISA-Agência Nacional de Vigilância Sanitária. Para este levantamento foram realizadas visitas nos lotes e questionário com as mulheres sobre as formas de usos e plantios das ervas, bem como grupos focais.

\section{Apresentação dos dados}

A análise foi realizada no intervalo de 1979 a 2016, nos banco da CAPES e Scielo, cruzando com a revisão da literatura publicada pelo IPEA ${ }^{2}$ em 2009. O filtro utilizado para selecionar os trabalhos que se alocassem na temática desta revisão foram mulheres, ervas medicinais e conhecimentos tradicionais. Neste sentido, conseguiu-se um fluxo significativo de trabalhos no período.

A primeira análise disponibilizada no quadro abaixo (quadro 1) foi a partir do relatório do estado da arte sobre gênero no meio rural de 1979 a 2009 realizado pelo IPEA. Se comparado com o quadro (quadro-2) das políticas educacionais aprovadas para o campo no mesmo período, podemos aproximar o aumento significativo de trabalhos sobre a temática pelo fato da criação de cursos de graduação, mestrados, doutorados e especializações destinados ao público do campo, nos quais, os alunos destes projetos desenvolvem as temáticas de seus trabalhos de conclusão sobre questões rurais. Verifica-se esse crescimento especialmente no período de 2001 a 2009, conforme descrito na tabela 1:

Tabela1 - Distribuição do número de trabalhos acadêmicos por ano - 1979/2009.

\begin{tabular}{c|c|c|c|c|c|c}
\hline $\begin{array}{c}\text { A n o d a } \\
\text { produção }\end{array}$ & $\begin{array}{c}\text { Produçõ es } \\
\text { EMBRAPA }\end{array}$ & Livros & $\begin{array}{c}\text { Artigos e m } \\
\text { periódicos }\end{array}$ & $\begin{array}{c}\text { Teses, dissertações e } \\
\text { monografias. }\end{array}$ & $\begin{array}{c}\text { O t r a s } \\
\text { publicações }\end{array}$ & Total \\
\hline $1979-1989$ & - & 2 & 1 & 15 & - & 18 \\
\hline $1990-2000$ & 3 & 15 & 8 & 75 & - & 101 \\
\hline $2001-2009$ & 7 & 17 & 42 & 163 & 8 & 237 \\
\hline
\end{tabular}

Fonte: Elaborado pelas autoras.

Pode-se dizer que houve um amadurecimento e aumento das ações educativas dos movimentos relacionados ao campo, tanto no que se refere ao foco de luta, quanto às conquistas direcionadas às políticas educacionais do campo, que favoreceram, de certa maneira, o aumento das ações nas áreas de educação do campo, o que veio a viabilizar pesquisas sobre estas novas ações. O quadro 1, destaca as principais políticas, programas ou projetos aproados no período:

${ }^{2}$ IPEA. Relatório IPEA gênero no meio rural 1979-2000. 
Quadro 1- Políticas Educacionais destinadas ao campo no período 2001 -2009.

\begin{tabular}{|c|c|c|}
\hline $\begin{array}{l}\text { Avanços/ } \\
\text { conquistas }\end{array}$ & Qualificação & Desdobramentos \\
\hline Lei $\mathrm{n}^{\circ} 10.639 / 03$ & $\begin{array}{l}\text { Ensino da história e cultura afro-brasileira } \\
\text { modifica a Lei no } 9.394 / 06 \text { e estabelece as } \\
\text { diretrizes e bases da educação nacional, } \\
\text { para incluir no currículo oficial da rede } \\
\text { de ensino a obrigatoriedade da temática } \\
\text { "História e Cultura Afro-Brasileira e } \\
\text { Indígena". }\end{array}$ & $\begin{array}{l}\text { A obrigatoriedade da inclusão da história e cultura afro- } \\
\text { brasileira permitiu o surgimento de inúmeros novos projetos } \\
\text { de valorização e conhecimento dos grupos alijados pela questão } \\
\text { étnica. E levou à aprovação da lei n }{ }^{\circ} 11.645 / 08 \text {. } \\
\text { Também levou ao fato de que o calendário escolar deverá } \\
\text { adequar-se às peculiaridades locais, inclusive climáticas e } \\
\text { econômicas, a critério do respectivo sistema de ensino, sem, } \\
\text { com isso, reduzir o número de horas letivas previsto nesta Lei. }\end{array}$ \\
\hline $\begin{array}{l}\text { Parecer } n^{\circ} 1 / 2006 \text { que } \\
\text { reconhece os Dias } \\
\text { Letivos da Alternância, } \\
\text { também homologado } \\
\text { pela CEB; }\end{array}$ & $\begin{array}{l}\text { Permitiu o reconhecimento dos cursos } \\
\text { com base na Alternância (CEEFA) para } \\
\text { a certificação de seus alunos. }\end{array}$ & $\begin{array}{l}\text { Foi possível o desenvolvimento de inúmeros cursos também } \\
\text { ligados à graduação e à pós-graduação para alunos do campo. }\end{array}$ \\
\hline Lei no $11.645 / 08$ & $\begin{array}{l}\text { Estabelece a obrigatoriedade do estudo } \\
\text { da história e cultura afro-brasileira e } \\
\text { indígena nos estabelecimentos de ensino } \\
\text { fundamental e de ensino médio públicos } \\
\text { e privados em todo o país. }\end{array}$ & $\begin{array}{l}\text { Permitiu a inclusão, no ensino público e particular, de temas } \\
\text { anteriormente submetidos ao saber dominante e que passam a } \\
\text { ser vistos sob a ótica dos grupos indígenas, e o desenvolvimento } \\
\text { de inúmeros projetos ligados a essa temática em todo Brasil. }\end{array}$ \\
\hline $\begin{array}{l}\text { Diretrizes Operacionais } \\
\text { para Educação Básica } \\
\text { das Escolas do Campo: } \\
\text { Resolução CNE/CEB n } \\
1 / 2002 \text {. }\end{array}$ & $\begin{array}{l}\text { Institui Diretrizes Operacionais para a } \\
\text { Educação Básica nas Escolas do Campo. }\end{array}$ & $\begin{array}{l}\text { Permitiu o desenvolvimento efetivo do projeto de Educação do } \\
\text { campo como política nacional. }\end{array}$ \\
\hline $\begin{array}{l}\text { Resolução CNE/CEB nº } \\
2 / 2008 \text {. }\end{array}$ & $\begin{array}{l}\text { Estabelece diretrizes complementares, } \\
\text { normas e princípios para o } \\
\text { desenvolvimento de políticas públicas } \\
\text { de atendimento da Educação Básica do } \\
\text { Campo. }\end{array}$ & $\begin{array}{l}\text { Os professores com formação em Curso Normal Superior } \\
\text { e em Pedagogia, dada sua formação, devem atuar de forma } \\
\text { multidisciplinar na Educação Infantil e nos anos iniciais do } \\
\text { Ensino Fundamental, o que não atinge o } 3^{\circ} \text { ano do } 2^{\circ} \text { Ciclo; } \\
\text { Os licenciados em Artes Plásticas, Artes Cênicas, Educação } \\
\text { Musical, Língua Estrangeira e Educação Física, por força da } \\
\text { forma inter-relacionada com que esses conteúdos se apresentam, } \\
\text { podem atuar em quaisquer dos ciclos de aprendizagem do Ensino } \\
\text { Fundamental, com o cuidado de desenvolvê-los de forma não } \\
\text { fragmentada e integrados à forma multidisciplinar, no caso dos } \\
\text { anos iniciais do Ensino Fundamental; } \\
\text { Enquanto não houver uma radical mudança na forma específica } \\
\text { e disciplinar da maior parte dos cursos de licenciatura e tendo } \\
\text { em vista a impossibilidade de o docente atuar "no ensino da sua } \\
\text { especialidade", posto que inexistente na atuação multidisciplinar, } \\
\text { os docentes oriundos das licenciaturas específicas devem atuar } \\
\text { nos campos específicos curriculares, desta forma organizados } \\
\text { nas séries finais do Ensino Fundamental e do Ensino Médio. }\end{array}$ \\
\hline $\begin{array}{l}\text { Lei } n^{\circ} 11.947 \text {, de } 16 \\
\text { de junho de } 2009 . \\
\text { Especialmente o artigo } \\
14\end{array}$ & $\begin{array}{l}\text { Dispõe sobre o atendimento da } \\
\text { alimentação escolar e do Programa } \\
\text { Dinheiro Direto na Escola aos alunos da } \\
\text { educação básica; altera as Leis nos } 10.880, \\
\text { de } 9 \text { de junho de } 2004 ; 11.273 \text {, de } 6 \text { de } \\
\text { fevereiro de } 2006 ; 11.507 \text {, de } 20 \text { de julho } \\
\text { de } 2007 \text {; revoga dispositivos da Medida } \\
\text { Provisória no } 2.178-36 \text {, de } 24 \text { de agosto } \\
\text { de } 2001 \text {, e a Lei no } 8.913 \text {, de } 12 \text { de julho } \\
\text { de } 1994 \text {; e dá outras providências. }\end{array}$ & $\begin{array}{l}\text { O artigo 14., ao propor que o total dos recursos financeiros } \\
\text { repassados pelo FNDE, no âmbito do PNAE, no mínimo } \\
30 \% \text { na aquisição de gêneros alimentícios diretamente da } \\
\text { agricultura familiar e do empreendedor familiar rural ou } \\
\text { de suas organizações, priorizando-se os assentamentos da } \\
\text { reforma agrária, as comunidades tradicionais indígenas e } \\
\text { comunidades quilombolas, permite a reafirmação, inclusive no } \\
\text { projeto educacional brasileiro, da importância do rural e destas } \\
\text { populações para segurança alimentar nacional. }\end{array}$ \\
\hline $\begin{array}{l}\text { Decreto } \mathrm{n}^{\circ} 7.352 \text {, de } 4 \text { de } \\
\text { novembro de } 2010 .\end{array}$ & $\begin{array}{l}\text { Dispõe sobre a Política Nacional de } \\
\text { Educação do Campo e sobre o Programa } \\
\text { Nacional de Educação na Reforma } \\
\text { Agrária (Pronera). Destaque-se, também, } \\
\text { o reconhecimento das especificidades } \\
\text { sociais, culturais, ambientais, políticas e } \\
\text { econômicas, do modo de produzir a vida } \\
\text { no campo. }\end{array}$ & $\begin{array}{l}\text { A política de Estado, para superação de limites existentes na } \\
\text { execução de programas de governo, sem nenhuma garantia de } \\
\text { permanência e continuidade. }\end{array}$ \\
\hline
\end{tabular}

Fonte: Adaptado de GOMES, 2015 e 2017. 
Vale destacar também que as agências de fomento também passaram a ser injetadas com mais verbas para as áreas "menos interessantes" do ponto de vista tecnocrático dominante. Entre estas políticas, destacamos algumas de maior relevância aprovadas no período em destaque - no primeiro quadro acima.

No que se refere ainda à primeira tabela, destaca-se que, no intervalo de 1979-2009 (Quadro 2), foram encontradas seis pesquisas diretamente ligadas ao tema deste trabalho, com destaque para os anos de 1996, 1997, 2000 e 2003, dos quais se encontram os títulos listados a seguir:

Quadro 2 - Trabalhos relacionados com o tema no intervalo de 1979 a 2009.

\begin{tabular}{|c|l|l|}
\hline Ano de produção & \multicolumn{1}{|c|}{ Título } & \multicolumn{1}{|c|}{ Autor } \\
\hline 1996 & $\begin{array}{l}\text { As benzedeiras e os benzedores de Três } \\
\text { Barras: a concepção do homem sagrado }\end{array}$ & Ribeiro, Maristela Guimarães \\
\hline 1997 & $\begin{array}{l}\text { Quatro grupos, quatro ONGs: um estudo } \\
\text { sobre agricultura e organização não } \\
\text { governamental em projetos de geração } \\
\text { de trabalho e renda no Nordeste. }\end{array}$ & Azevedo, Maria Andrade de \\
\hline 1997 & $\begin{array}{l}\text { Levantamento das plantas de uso } \\
\text { medicinal em Coronel Bianco - RS. }\end{array}$ & Kubo, Runi Regina \\
\hline 2000 & $\begin{array}{l}\text { Levantamento das plantas medicinais } \\
\text { usadas no município de Cruz Alta- RS } \\
\text { Brasil }\end{array}$ & Garlet, Tânia \\
\hline 2003 & Educação, cultura popular e saúde. & Daron, Vanderleia Laodete \\
\hline 2003 & $\begin{array}{l}\text { Como ervas dos montes e águas da fonte: } \\
\text { estudo de benzedeiras e benzedores da } \\
\text { zona rural Santa Rosa do Sul }\end{array}$ & Galinha, Jaqueline Posses \\
\hline & & \\
\hline
\end{tabular}

Fonte: Elaborado pelas autoras.

Os trabalhos acima listados referem-se a estudos em assentamentos de reforma agrária, relacionados às ervas medicinais, ora ligados ao sentido sagrado, ora às práticas típicas de cuidados femininos. $\mathrm{O}$ ponto interessante é que todos os trabalhos estão relacionados a autoras mulheres, o que, sem dúvida, evidencia um interesse propriamente de uma questão de gênero, ou, quem sabe, do "Sagrado Feminino".

É preciso ainda destacar que, no tocante ao intervalo de 2011 a 2016, segundo o Banco de teses e dissertações da CAPES, o número de trabalhos relacionados à temática sobre ervas medicinais também teve um aumento significativo. Esse aumento, em parte, está relacionado às políticas de educação que promoveram cursos do PRONERA- Programa Nacional de Educação na Reforma Agrária destinados à formação de quem está no campo, o que, sem dúvidas, aumentou enormemente o número de trabalhos publicados, como observado na tabela 2.

Os dados (Tabela 2) mostram dois momentos significativos: o de 2013 e o de 2015, que se relacionam a datas significativas de aprovação de legislação referente às práticas e/ou aos usos das ervas medicinais ou chamados de fitoterápicos. Isso significa dizer que, no que se refere estritamente ao aspecto legal das práticas ligadas aos usos das ervas medicinais, houve um aumento significativo e qualitativo da normalização brasileira.

É possível dizer que, hoje, o Brasil é um dos países com legislação mais avançada do mundo referente aos fitoterápicos, processo que se iniciou em 1981, com a Portaria no 212, de 11 de setembro de 1981. A partir de então, o país passa a adotar as plantas medicinais como prioridade, e, no ano seguinte, elas 
passam a ser incluídas na lista da Central de medicamentos por meio do Programa de Pesquisa de Plantas Medicinais.

Tabela 2 - Número de trabalhos sobre a temática ervas medicinais de 2011-2016.

\begin{tabular}{c|c}
\hline Ano & Quantidade \\
\hline 2011 & Sem dados \\
\hline 2012 & 439 \\
\hline 2013 & 482 \\
\hline 2014 & 459 \\
\hline 2015 & 541 \\
\hline 2016 & 391 \\
\hline
\end{tabular}

Fonte: Produzido pelas autoras a partir da base de dados da CAPES.

Em 1988, a Resolução CIPLAN-08/88 regulamenta a implantação da fitoterapia nos Serviços de Saúde, nas Unidades Federativas, e, em 1991, o Parecer n06/91 do Conselho de Medicina reconhece a atividade de fitoterapia, desenvolvida sob supervisão médica, como uma prática referendada pelo Ministério da Saúde.

Mas é efetivamente a partir de 2004 que ocorreram avanços verdadeiramente significativos. Neste ano, foram publicadas a Resolução $n^{\circ} 90$, relativa à Guia para a realização de estudos de toxicidade préclínica de fitoterápicos, e também a Resolução da Diretoria Coletiva n48, que dispõe sobre o registro de medicamentos fitoterápicos.

Em 2008, foi então criada a PNPMF - Política Nacional de Plantas Fitoterápicas - (BRASIL, 2006a) e também publicada a Instrução Normativa no 5 , que regulamenta 36 espécies de plantas medicinais de registro simplificado junto à ANVISA (BRASIL, 2008).

Além deste grupo, foram ainda publicadas as RENISUS e RDC n¹0: a primeira é uma Relação Nacional de Plantas Medicinais de Interesse do SUS, a qual lista 71 espécies de interesse do SUS; e a segunda se refere à resolução da ANVISA que regulamenta a comercialização das drogas vegetais de venda isenta de prescrição médica destinada ao consumidor final. Neste mesmo ano, foram ainda aprovadas a RDC $\mathrm{n}^{\circ} 14$, que dispõe sobre o registro de medicamentos fitoterápicos, e a RDC n 17 , que dispõe sobre as Boas Práticas de Fabricação de medicamentos. Por fim, a portaria ${ }^{\circ} 886$, de 2009, institui a Farmácia Viva no âmbito do SUS.

No que se refere à legislação atual e ao relativo aumento de trabalhos publicados no período relacionado anteriormente (2013 e 2015), destaca-se inicialmente, em 2011, o lançamento da 5a edição da Farmacopeia Brasileira (BRASIL, 2010a, 2010b), que descreve 52 plantas medicinais, na forma de droga vegetal. Em 2012, há a publicação da 1a edição do Formulário Fitoterápico da Farmacopeia Brasileira (BRASIL, 2011), apresentando 54 plantas medicinais, na forma de droga vegetal, tintura, gel, pomada, creme, xarope e sabonete.

Aqui cabe uma observação: se verificarmos o ano de 2013, não há legislação publicada este ano, mas há um número significativo de trabalhos publicados no período, muito maior do que no ano anterior (cerca de 40), fato que pode estar relacionado à produção científica voltada à valorização dos fitoterápicos, como destacado nas leis, o que provavelmente foi resultado de pesquisas que geraram a descrição de 52 plantas no ano 2011 e de outras 54 em 2012.

Ainda sobre a legislação, podemos destacar que, no ano de 2014, com a publicação da RDC No 26, de 13 de maio de 2014 (BRASIL, 2014c), e da IN No 4, de 18 de junho de 2014 (BRASIL, 2014b), o país passou 
a ter "dois tipos de produtos com finalidade medicinal derivados de plantas: o medicamento fitoterápico (MF) e o produto tradicional fitoterápico (PTF)"”.

Na mesma perspectiva de número de produção de trabalhos relacionados às ervas medicinais, verificamos também, em 2015, um salto de cerca de 40 trabalhos a mais de produção no período. Um provável resultado de trabalhos científicos concluídos e publicados posteriormente à legislação aprovada.

Nesta tabela 3 podem ser verificados os principais temas encontrados de acordo com a relação de palavras chave relacionados ao presente trabalho.

Tabela 3 - Pesquisa bibliográfica de teses e dissertações de 2011 a 2016- CAPES.

\begin{tabular}{|c|c|c|}
\hline Filtro utilizado no banco da CAPES & Quantidade & $\begin{array}{l}\text { Filtro área da educação (ou áreas } \\
\text { afins) e faculdade de educação }\end{array}$ \\
\hline Patrimônio imaterial & 7839 & 261 \\
\hline Ervas medicinais & 5290 & 3753 (outras áreas) \\
\hline $\begin{array}{c}\text { Conhecimento tradicional de mulheres } \\
\text { assentadas }\end{array}$ & 900690 & 6409 \\
\hline $\begin{array}{c}\text { Processamento de ervas medicinais por } \\
\text { mulheres assentadas }\end{array}$ & 900712 & 6409 \\
\hline $\begin{array}{c}\text { Práticas agroecológicas através do resgate } \\
\text { de saberes tradicionais }\end{array}$ & 901030 & 6413 \\
\hline \multirow{4}{*}{$\begin{array}{l}\text { Patrimônio imaterial, gênero, } \\
\text { assentamentos rurais, ervas medicinais, } \\
\text { agroecologia }\end{array}$} & \multirow[t]{4}{*}{64951} & \begin{tabular}{|c|}
752 (área: Educação/ Linguagem e \\
letramento)
\end{tabular} \\
\hline & & 500 (programa: Educação) \\
\hline & & 155 (filtro universidades públicas) \\
\hline & & $\begin{array}{c}1 \text { com relação direta com o tema do } \\
\text { trabalho }^{5}\end{array}$ \\
\hline $\begin{array}{c}\text { "Patrimônio imaterial, agroecologia, } \\
\text { mulheres e ervas medicinais" }\end{array}$ & $\begin{array}{l}\text { Palavras-chave } \\
\text { usadas, especificadas } \\
\text { com aspas: nada } \\
\text { consta }\end{array}$ & 0 \\
\hline
\end{tabular}

Fonte: Elaborado pelas autoras.

\footnotetext{
${ }^{3}$ Ibdem.

${ }^{4}$ A revisão realizada refere-se ao intervalo de 2011 a 2016.

${ }^{5} \mathrm{O}$ trabalho encontrado relacionado à presente pesquisa é: DARON, VANDERLEIA LAODETE PULGA. Mulheres camponesas plantando saúde, semeando sonhos, tecendo redes de cuidado e de educação em defesa da vida’ 12/12/2014. 197 f. Doutorado em educação instituição de ensino: Universidade Federal do Rio Grande do Sul, Porto Alegre - biblioteca depositária: Central da UFRGS.
} 
Finalmente, no que se refere propriamente à revisão de 2011 a 2016 do banco de teses e dissertações da CAPES, destaca-se que, para cada palavra-chave do presente trabalho, foi realizado o filtro de área de conhecimento, programa e universidades públicas. Seguindo respectivamente a ordem: área do conhecimento - Educação, Programa - Educação, Universidade: Pública.

Foram realizadas combinações diferenciadas de palavras que ajudariam a encontrar um campo de trabalhos que orientasse na construção final da pesquisa. No entanto, nas combinações de palavras-chaves: patrimônio imaterial, ervas medicinais, conhecimento tradicional de mulheres assentadas, processamento de ervas medicinais por mulheres assentadas e práticas agroecológicas através do resgate de saberes tradicionais; o número de trabalhos listados foi gigantesco. No entanto, a partir dos filtros propostos, chegou-se a 155 resumos. A partir da leitura destes, encontrou-se apenas um trabalho com relação direta com a pesquisa desenvolvida: "Mulheres camponesas plantando saúde, semeando sonhos, tecendo redes de cuidado e de educação em defesa da vida”.

\section{Perfil da PRodução de erVas medicinais das mulheres entrevistadas}

Dentre os dados levantados no perfil produtivo, partimos das 66 ervas descritas e regulamentadas pela ANVISA-Agência Nacional de Vigilância Sanitária ${ }^{6}$ - por meio da resolução RDC No 10 , de 9 de março de 2010. Estas são indicadas como medicamentos complementares aos alopáticos. No quadro 3, é possível identificar o nome científico das espécies e a parte utilizada para realização do chá ou medicamento.

Segundo esta resolução, compreende-se por chá: "o produto que deve ser designado de "Chá", seguido do nome comum da espécie vegetal utilizada, podendo ser acrescido do processo de obtenção e ou característica específica. Podem ser utilizadas denominações consagradas pelo uso" (RDC No10/2010). É importante salientar que foram levantados outros tipos de ervas, que não estavam nesta listagem, mas dos quais há um amplo uso na prática popular e até na literatura científica, embora ainda não tenham sido acrescentados à listagem de interesse do SUS segundo a ANVISA.

No que tange propriamente ao perfil produtivo dos lotes das mulheres visitadas durante o projeto, verificou-se, a priori, que as ervas são produzidas no espaço próximo ao da casa, junto à horta doméstica ou em canteiros junto ao pomar. Para um olhar desatento, algumas podem ser até consideradas mato ou erva daninha, mas, para olhos atentos, são matéria-prima básica de remédios, repelentes ou pomadas, que são mais eficientes quando produzidas destas formas (Imagens 1 e 2).

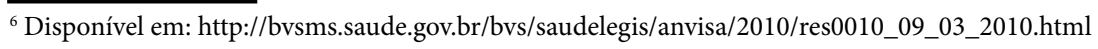


Quadro 3 - Espécies vegetais para preparo de chás segundo informe técnico nº45/1.

\begin{tabular}{|c|c|}
\hline NOME COMUM / NOME CIENTÍFICO & Parte do vegetal utilizada \\
\hline Abacaxi / Bromelia ananas L. & infrutescência (casca e polpa dos frutos) \\
\hline Acerola / Malpighia glabra L. & frutos \\
\hline Ameixa / Prunus domestica L. & frutos \\
\hline Amora / Rubus spp & frutos \\
\hline Ananás / Ananas sativus Schult. \& Schult. F & polpa dos frutos \\
\hline Ananás / Ananas sativus Schult. \& Schult. F & $\begin{array}{l}\text { infrutescência (casca e polpa } \\
\text { dos frutos) }\end{array}$ \\
\hline Banana caturra e banana-nanica / Musa sinensis L. & frutos \\
\hline $\begin{array}{l}\text { Banana-de-são-tomé, banana-maçã, banana-ouro, } \\
\text { banana-prata / Musa romática a L. }\end{array}$ & frutos \\
\hline Banana-da-terra / Musa sapientum L. & frutos \\
\hline Baunilha / Vanilla romática Swart. & Frutos \\
\hline Boldo / Pneumus boldus Molina (1) & folhas \\
\hline Beterraba / Beta vulgaris L. & raízes \\
\hline Chamomilla recutita (L.) Rauscher & \\
\hline $\begin{array}{l}\text { Capim-limão ou capim-santo ou capim-cidreira ou } \\
\text { capim-cidró ou chá de Estrada / Cymbopogon citratus } \\
\text { Stapf }\end{array}$ & sfolhas \\
\hline Carqueja/Baccharis genistelloides (Lamarck) Persoon & folhas \\
\hline Cassis ou groselha negra / Ribes nigrum L. & frutos \\
\hline Cereja / Prunus serotina Ehrh & frutos (sem semente) \\
\hline $\begin{array}{l}\text { Chá preto ou chá verde ou chá branco/ Camellia } \\
\text { sinensis (L.) Kuntze }\end{array}$ & folhas e talos \\
\hline Chicória / Cichorium intybus L. (2) & Folhas, talos e raízes \\
\hline Cenoura / Daucus carota L. & raízes \\
\hline Damasco ou Apricot / Prunus armeciaca L & frutos (sem semente) \\
\hline Erva-cidreira ou melissa / Melissa officinalis L. & folhas e ramos \\
\hline $\begin{array}{l}\text { Erva-mate ou mate verde ou mate tostado/ Ilex } \\
\text { paraguariensis St. Hil. }\end{array}$ & Folhas e talos \\
\hline $\begin{array}{l}\text { Erva-doce ou anis ou anis doce / Pimpinella anisum } \\
\text { L. }\end{array}$ & frutos \\
\hline Estévia / Stevia rebaundiana Bert (2) & folhas \\
\hline Framboesa / Rubus idaeus L. & frutos \\
\hline $\begin{array}{l}\text { Funcho ou erva-doce-nacional / Foeniculum vulgare } \\
\text { Mill. }\end{array}$ & Frutos \\
\hline Groselha / Ribes rubrum L. & frutos \\
\hline Guaraná / Paullinia cupana L. & sementes \\
\hline Hibisco / Hibiscus sabdariffa L. & flores \\
\hline $\begin{array}{l}\text { Hortelã ou Hortelã Pimenta ou Menta /Mentha } \\
\text { piperita L }\end{array}$ & folhas e ramos \\
\hline $\begin{array}{l}\text { Hortelã ou Menta ou Hortelã doce ou Menta doce / } \\
\text { Mentha arvensis L }\end{array}$ & folhas e ramos \\
\hline Jasmim / Jasminum officinale L. & flores \\
\hline $\begin{array}{l}\text { Laranja amarga e laranja-doce / Citrus aurantium L. } \\
\text { ou Citrus vulgaris Risso e Citrus sinensis Osbeck }\end{array}$ & frutos, casca dos frutos, folhas e flores \\
\hline $\begin{array}{l}\text { Limão e limão-doce / Citrus limmonia Osbeck ou } \\
\text { Citrus limonium Risso }\end{array}$ & ufrutos, casca dos frutos, folhas e flores \\
\hline Maçã / Pyrus malus L. & frutos \\
\hline Mamão ou papaia / Carica papaya L. & frutos \\
\hline Manga / Mangifera indica L. & frutos \\
\hline Maracujá-açú / Passiflora quadrangularis L. & polpa dos frutos \\
\hline
\end{tabular}

Fonte: ANVISA - Informe Técnico n 45 , de 28 de dezembro de $2010^{7}$.

\footnotetext{
${ }_{7}^{7}$ Disponível em: <https://edisciplinas.usp.br/pluginfile.php/3474733/mod_resource/content/1/Informe\%20T\%C3\%A9cnico\%20n\%C2\%BA\%20 $45 \% 2 \mathrm{C} \% 20 \mathrm{de} \% 2028 \% 20 \mathrm{de} \% 20$ dezembro\%20de $\% 202010 \% 20 \% 281 \% 29$.pdf $>$.
} 
Segundo esta resolução, compreende-se por chá: "o produto que deve ser designado de "Chá", seguido do nome comum da espécie vegetal utilizada, podendo ser acrescido do processo de obtenção e ou característica específica. Podem ser utilizadas denominações consagradas pelo uso" (RDC No10/2010). É importante salientar que foram levantados outros tipos de ervas, que não estavam nesta listagem, mas dos quais há um amplo uso na prática popular e até na literatura científica, embora ainda não tenham sido acrescentados à listagem de interesse do SUS segundo a ANVISA.

No que tange propriamente ao perfil produtivo dos lotes das mulheres visitadas durante o projeto, verificou-se, a priori, que as ervas são produzidas no espaço próximo ao da casa, junto à horta doméstica ou em canteiros junto ao pomar. Para um olhar desatento, algumas podem ser até consideradas mato ou erva daninha, mas, para olhos atentos, são matéria-prima básica de remédios, repelentes ou pomadas, que são mais eficientes quando produzidas destas formas, como verificado nas Fotos 1 e 2.

Fotos 1 e 2 - Produção de ervas nos quintais.
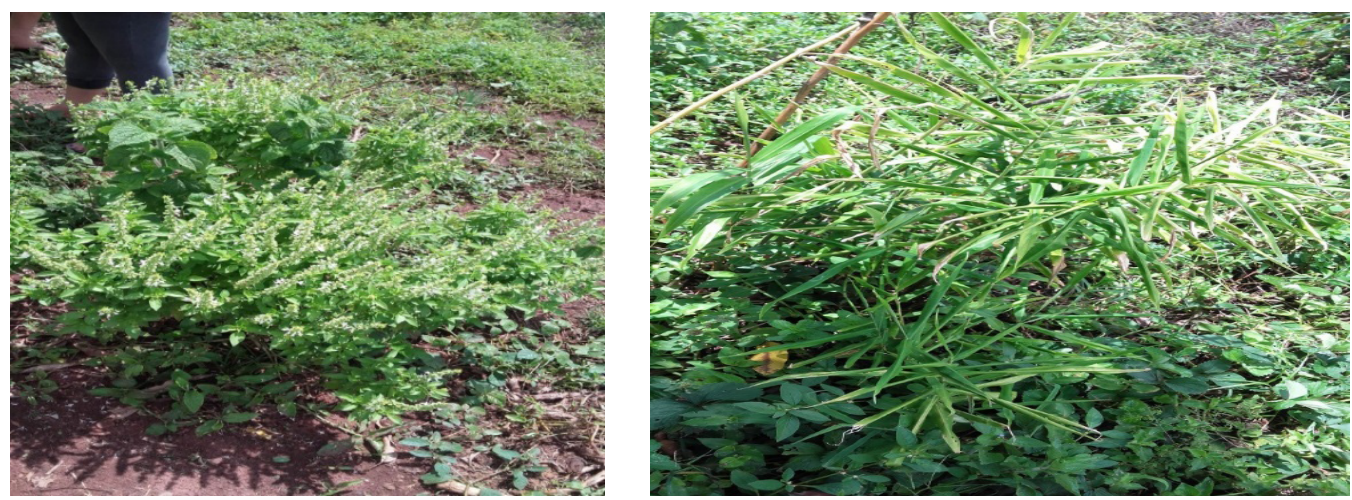

Fonte: Acervo das autoras.

Neste sentido, partindo da listagem da ANVISA, nos lotes inventariados, foram encontrados 40 tipos do total de ervas listado, o que equivale a mais de $60 \%$ desta listagem. Na tabela 4 , estão elencadas as ervas encontradas da listagem inicial.

Além destas ervas, foram ainda identificadas outras também usadas como temperos e ervas aromáticas muito utilizadas popularmente para alimentação, cosméticos ou remédios, que são comercializadas em lojas especializadas (Tabela 5). 
Tabela 4 - Listagem das ervas da ANVISA segundo RDC nº 10 encontradas nos lotes inventariados.

\begin{tabular}{|c|c|c|}
\hline Ervas regulamentadas pela ANVISA & $\begin{array}{l}\text { Número de lotes } \\
\text { com as ervas }\end{array}$ & $\begin{array}{l}\text { Porcentagem de lotes que } \\
\text { produzem as ervas } \%\end{array}$ \\
\hline Alecrim - Rosmarinus officinalis & 10 & 62,5 \\
\hline Alho - Allium sativum & 4 & 25 \\
\hline Anis estrelado - Illicium verum & 2 & 12,5 \\
\hline Anis, Erva doce - Pimpinela anisum & 3 & 18,75 \\
\hline Arnica - Arnica montana & 5 & 31,25 \\
\hline Aroeira da praia - Schinus terebinthifolia & 2 & 12,5 \\
\hline Assa peixe - Vernonia polyanthes & 2 & 12,5 \\
\hline Barbatimão - Stryphnoden dromadstrigens & 5 & 31,25 \\
\hline Boldo do chile - Peumus boldus & 8 & 50 \\
\hline $\begin{array}{l}\text { Boldo nacional, Hortelã homem, Falso boldo, Boldo africano - } \\
\text { Plectranthus barbatus }\end{array}$ & 6 & 37,5 \\
\hline Cajueiro - Anacardium occidentale & 6 & 37,5 \\
\hline Canela - Cinnamomum verum & 2 & 12,5 \\
\hline $\begin{array}{l}\text { Capim santo, Capim limão, Capim cidreira, Cidreira - Cymbopogon } \\
\text { citratus }\end{array}$ & 11 & 68,75 \\
\hline Cavalinha - Equisetum arvense & 2 & 12,5 \\
\hline Chapéu de couro - Echinodorus macrophyllus & 2 & 12,5 \\
\hline Curcuma, Açafrão da Terra - Curcuma longa & 4 & 25 \\
\hline Dente de leão - Taraxacum officinale & 3 & 18,75 \\
\hline Erva cidreira, Falsa melissa - Lippia alba & 12 & 75 \\
\hline Erva de bicho, Pimenteira dágua - Polygonum punctatum & 1 & 6,25 \\
\hline Eucalipto - Eucalyptus globulus & 8 & 50 \\
\hline Gengibre - Zingiber officinale & 7 & 43,75 \\
\hline Goiabeira - Psidium guajava & 13 & 81,25 \\
\hline Guaco - Mikania glomerata & 2 & 12,5 \\
\hline Guaraná - Paullinia cupana & 1 & 6,25 \\
\hline Hortelã pimenta - Mentha x piperita & 11 & 68,75 \\
\hline Jucá, Pau ferro - Caesalpinia ferrea & 1 & 6,25 \\
\hline Jurubeba-Solanum paniculatum & 7 & 43,75 \\
\hline Laranja amarga - Citrus aurantium & 3 & 18,75 \\
\hline Macela, Marcela - Achyrocline satureioides & 4 & 25 \\
\hline Maracujá - Passiflora alata & 11 & 68,75 \\
\hline Maracujá azedo - Passiflora edulis & 6 & 37,5 \\
\hline Melão de São Caetano - Momordica charantia & 7 & 43,75 \\
\hline Melissa, Erva cidreira - Melissa officinalis & 3 & 18,75 \\
\hline Mentrasto, Catinga de bode - Ageratum conyzoides & 8 & 50 \\
\hline Picão - Bidens pilosa & 13 & 81,25 \\
\hline Pitangueira - Eugenia uniflora & 6 & 37,5 \\
\hline Poejo - Mentha pulegium & 1 & 6,25 \\
\hline Quebra pedra - Phyllanthus niruri & 10 & 62,5 \\
\hline Romã - Punica granatum & 10 & 62,5 \\
\hline Sabugueiro - Sambucus nigra & 2 & 12,5 \\
\hline
\end{tabular}

Fonte: Elaborado pelas autoras. 
Tabela 5 - Outras ervas produzidas nos lotes inventariados na pesquisa.

\begin{tabular}{|l|c|c|}
\hline Outras ervas e temperos & $\begin{array}{c}\text { Número de lotes } \\
\text { com as ervas }\end{array}$ & $\begin{array}{c}\text { Porcentagem de lotes que } \\
\text { produzem ervas em \% }\end{array}$ \\
\hline Araruta & 1 & 6,25 \\
\hline Balsamo & 1 & 6,25 \\
\hline Cebolinha & 5 & 31,25 \\
\hline Chia & 1 & 6,25 \\
\hline Citronela & 2 & 12,5 \\
\hline Coentro & 3 & 18,75 \\
\hline Estomalina & 1 & 6,25 \\
\hline Favoca/alfavoca & 1 & 6,25 \\
\hline Figo & 1 & 6,25 \\
\hline Levanti & 2 & 12,5 \\
\hline Louro & 2 & 12,5 \\
\hline Manjericão & 3 & 18,75 \\
\hline Menta & 1 & 6,25 \\
\hline Noni & 1 & 6,25 \\
\hline Orégano & 1 & 6,25 \\
\hline Pimenta do reino & 1 & 6,25 \\
\hline Salsinha & 4 & 25 \\
\hline Urucum & 3 & 18,75 \\
\hline
\end{tabular}

Fonte: Elaborado pelas autoras.

O quadro reflete tanto a diversidade presente nos quintais biodiversos destas mulheres como uma preocupação de cultivar ervas o que de alguma forma são utilizadas por estas mulheres, seja em forma de medicamentos, seja em forma de repelentes de pragas, insetos ou animais. O saber sobre estas plantas é muitas vezes parte do processo de repasse oral e tradicional, mas também do processo de observação diário e acompanhamento dos fenômenos naturais que representam um laboratório da vida real.

\section{Considerações Finais}

Parte de toda esta diversidade se faz pela valorização de conhecimentos advindos hereditariamente, em que se usava um chá ou um tipo de alimento de outra região do país e no embolado de espécies se conservam como práticas cotidianas e saberes tradicionais. A valorização da vida é aqui entendida com proporções ainda maiores do que apenas a saúde individual, pois esta se faz através da relação universal de efeitos tão abrangentes que afetam não unicamente o corpo humano, mas as diferentes espécies, o clima e a própria relação com natureza e com as culturas tradicionais e agrícolas.

A partir disso, os saberes tradicionais e os conhecimentos adquiridos de forma geracional com o vivenciamento a partir da observação da natureza, predominante nas atividades femininas, são substituídos por práticas artificializadas e sintéticas, no caso da produção comercial. Neste aspecto, o papel feminino, como veremos no processo histórico, é duplamente importante, primeiro por serem as mulheres, em grande medida, responsáveis pela permanência da resistência de práticas alternativas frente ao sistema da agricultura convencional, e segundo por manterem vivos e repassarem um conhecimento sobre saúde, 
criação e meio ambiente mais sustentável às novas gerações.

Muitas das práticas naturais que a ciência tem chamado de Agroecologia e praticado em quintais, áreas da agrovila, pomares, sítios, hortinhas têm novamente a figura feminina como ponto central na sua organização e cuidado, o que permite a atribuição de protagonismo deste movimento inovador às mulheres.

\section{REFERÊNCIAS}

ANVISA. Ministério da Saúde. Atitude de ampliação de acesso (2006). Brasília: Ministério da Saúde. BRASIL. Farmacopeia Brasileira. Volume 1. 5a ed., Vol. 1, p. 523. Brasília: Agência Nacional de Vigilância Sanitária ANVISA, 2010a.

BRASIL. Farmacopeia Brasileira. Volume 2. 5a ed., Vol. 1, p. 808. Brasília: Agência Nacional de Vigilância Sanitária ANVISA, 2010b.

BRASIL. Formulário de Fitoterápicos da Farmacopeia Brasileira. Brasília: Agência Nacional de Vigilância Sanitária ANVISA, 2011.

BRASIL. Instrução Normativa (IN) no 2 de 13 de maio de 2014. Lista de medicamentos fitoterápicos de registro simplificado e Lista de produtos tradicionais fitoterápicos de registro simplificado. Agência Nacional de Vigilância Sanitária -ANVISA. Brasília: Diário Oficial da União, 2014.

BRASIL. Instrução Normativa (IN) no 4 de 18 de junho de 2014. Guia de orientação para registro de Medicamento Fitoterápico e registro e notificação de Produto Tradicional Fitoterápico. Agência Nacional de Vigilância Sanitária (ANVISA). Brasília: Diário Oficial da União, 2014.

BRASIL. Instrução Normativa (IN) no 5 de 11 de dezembro de 2008. Lista de Medicamentos Fitoterápicos de Registro Simplificado. Agência Nacional de Vigilância Sanitária (ANVISA). Brasília: Diário Oficial da União, 2008.

BRASIL. Política Nacional de Plantas Medicinais e Fitoterápicos. Brasília, 2006.

BRASIL. Política Nacional de Práticas Integrativas e Complementares no SUS. Brasília

BRASIL. Resolução de Diretoria Colegiada (RDC) no 10 de 09 de março de 2010. Notificação de drogas vegetais. Agência Nacional de Vigilância Sanitária -ANVISA. Brasília: Diário Oficial da União, 2010.

BRASIL. Resolução de Diretoria Colegiada (RDC) no 13 de 14 de março de 2013. Boas Práticas de Fabricação de Produtos Tradicionais Fitoterápicos. Agência Nacional de Vigilância Sanitária -ANVISA. Brasília: Diário Oficial da União, 2013.

BRASIL. Resolução de Diretoria Colegiada (RDC) no 26 de 13 de maio de 2014. Registro de medicamentos fitoterápicos e o registro e a notificação de produtos tradicionais fitoterápicos. Agência Nacional de Vigilância Sanitária -ANVISA. Brasília: Diário Oficial da União, 2014.

GOMES, T. P. de S. O multiculturalismo, movimentos sociais e educação do campo. In: VII Jornada 
Entre canteiros e ervas: um estudo da...

de Estudos em Assentamentos Rurais, 2015, Campinas. Anais VII Jornada de Estudos em Assentamentos Rurais, 2015.

Educação - Finalidades e objetivos. Educação não formal- Londrina: Editora e Distribuidora Educacional S.A., 2017. 